\title{
The Journal of Clinical Psychology in Medical Settings and the Association of Psychologists in Academic Health Centers
}

In January, 2006 the Journal of Clinical Psychology in Medical Settings will become the official journal of the Association of Psychologists in Academic Health Centers (APAHC). For the past 8 years, the Journal was a membership-benefit of APAHC (formerly known as the Association of Medical School Psychologists, e.g., Silver, Carr, \& Leventhal, 2005). APAHC is Section 8 of the Society of Clinical Psychology, Division 12, of the American Psychological Association.

APAHC's purpose is to promote and enhance the participation of psychologists in governance, research, education, and clinical services in academic health centers, teaching hospitals, and/or schools or colleges of health professions, medicine, nursing, dentistry, pharmacy, or public health. APAHC works to expand the role of psychology and the place of behavioral science in health care research, clinical services, and the psychology education for graduate students, pre-doctoral psychology interns, postdoctoral fellows, and medical students and resident physicians.
The Journal of Clinical Psychology in Medical Settings routinely has published special issues related to APAHC's national conferences or APAHC symposia at the annual convention of the American Psychological Association. As the official journal of the Association of Psychologist in Academic Health Centers, the members of the Association will receive continued electronic access to the Journal as a benefit of membership. Contact information for APAHC Officers is available at: http://www.apa.org/divisions/div12/sections/section8/ index.htm. The APAHC Administrative Office can be contacted at div12apa@comcast.net or $+1-303-652-3126$.

\section{REFERENCES}

R. J. Silver, J. E. Carr, G. Leventhal (2005). History of the Association of Medical School Psychologists (AMSP), 1982-2005. The Journal of Clinical Psychology in Medical Settings, 12, 235246 